\title{
Ageing and Secular Social Involvement: Exploring to Subjective Wellbeing
}

\author{
Rachmah Indawati $^{1}$, Kuntoro ${ }^{2}$, Hari Basuki Notobroto ${ }^{3}$, M. Bagus Qomaruddin ${ }^{4}$ \\ ${ }^{1,2,3}$ Department of Biostatistics and Population Study, Public Health School, Universitas Airlangga, Indonesia \\ ${ }^{4}$ Department of Health Promotion and Behavioral Sciences, Public Health School, Universitas Airlangga, Indonesia
}

\begin{tabular}{l}
\hline Article Info \\
\hline Article history: \\
Received Aug 25, 2016 \\
Revised Nov 11, 2016 \\
Accepted Nov 22, 2016 \\
\hline
\end{tabular}

Keyword:

Ageing

Elderly

Religious

Spiritual

Subjective well being

\begin{abstract}
Religion and Spirituality can provide a unique perspective on life outcomes. The study to deepen subjective wellbeing by exploring its relationships with religious and spirituality (secular values) and characteristics individual by the graph. Data were obtained from survey. The sample was drawn from the population aged 70 or more years in Surabaya by simple random sampling. The instrument using the Philadelphia geriatric center morale scale (PGCMS) and the self-spirituality and religious. Most respondents reported being 'low of religiosity and spirituality' in their lives. The mean PGCMS score was 7.89. The median PGCMS score was $8,57.4 \%$ (139) score PGCSM above the median and $42.6 \%$ (103) score PGCSM under the median. Among elderly who were included the high wellbeing category (PGCSM $\geq 10$ ) was $27.2 \%$ and most of elderly $72.7 \%$ didn't have good wellbeing. The elderly people who describe themselves as religious are showed graph constant. The graph of self-religious is equal according to characteristic individual (age, men and women, marital status). The elderly who describe themselves as spiritual are likely to report greater or lower perceived wellbeing. Exploring using the graph showed different according to characteristic individual. Elderly who demonstrated subjective wellbeing were more likely to male and not married. Elderly's perception of spirituality depends on characteristic individuals and experience in which individuals live.
\end{abstract}

Copyright $@ 2016$ Institute of Advanced Engineering and Science. All rights reserved.

\section{Corresponding Author:}

Rachmah Indawati,

Department of Biostatistics and Population Study,

Airlangga University,

Kampus C Fakultas Kesehatan Masyarakat Universitas Airlangga,

Jl. Mulyorejo Surabaya-60115, Jawa Timur, Indonesia.

Email: rachmah.indawati@gmail.com

\section{INTRODUCTION}

East Java has experienced a demographic transition. East Java is aging at a rapid pace because fertility declines and adults aged over $65+$ at $7.07 \%$ of the total population [1]. According the United nations population division (2002), Indonesia approximation older people to be among the highest in the world in the decades [2]. Some demographic characteristics are important to look at the phenomenon of the aging process. Socio-economic conditions at the individual level shows the percentage of the total labor force (in the age group 60+) are still lower. This means that most of the older age group is not productive. The percentage of the total workforce in some areas in East Java is still lower than the regional figure (5.07\%). Another phenomenon is the level of education shows that the percentage of the population (aged 15+ years) who have never been formal education is still high [3-5].

Indonesia is experiencing rapid economic growth before 1990 [6], it is characterized by the emergence of metropolitan cities in several regions in Indonesia. Based on data from the socio-economic conditions in East Java, East Java family faced a very serious level. Of the total population of 37,879,713 
inhabitants in East Java, there are poor families amounting to 1,464,233 families and 53.45\% are vulnerable families [3-5].

What about the elderly? Research is unveiling the elderly in several regions in Indonesia. It is said that the elderly are economically less got a chance compared to the average young person [7]. Thus economic conditions will lead to other problems. Based on data showing that serious social problems afflict the elderly is an act of violence that occur in some areas in East Java and the amount is very varied with a range of 0-171 cases [3].

Life expectancy is increasing in the region; there will be the aging of the population [8]. Life expectancy at birth in East Java continues to increase and has reached the age of 70 years. Some areas show a higher life expectancy than the figure in East Java in 2010 which is above 70 years. Conditions of rapid population aging are closely linked to health problems [1]. The proportion of elderly who have health complaints is more than $50 \%$. The percentage of women with health complaints bigger than males in all age groups [9-10].

Furthermore, in some European countries, the birth of this modernization led to a crisis of religion or so-called 'secularization'. As the main distinguishing feature of modern society is when the rational thinking has replaced the role of religion as a principle of social life [11]. The study tries to explain the value of life in society is now marked with a 'more modern' relates to the lives of elderly people in everyday life. Focus on the elderly 70+ years in the community who felt social change. Seniors have special developmental task that besides trying to get out of a crisis such as loss of life roles, pension, health problems [12] should also seek to control social environment and improve economic security. Religion plays a central role in the development of the moral order [13], religion provides a unique perspective on life outcomes. Faith affects outlook on life and experience of the elderly. Religious minded people who can pull of subjective elements of their spirituality in defining the conditions of life [14]. Some literature mentions that a good spiritual experience will have implications on mental health [15], association between life satisfaction [14], [16-17]. Spirituality seems to be a positive force on parents to let go of one phase of life and gain new life in another way [18].

Elderly people may or may not see social change in their lives but the conditions there are social forces tend to affect elderly people that need adaptation and feeling their life satisfaction in elderly [14]. The feeling of satisfaction is essential to the health of subjective. According Kodzi, et al., [14] related to life satisfaction, psychological and social implications. Sastre [19] says that some types of factors are studied wellbeing [19]. The first, dealing with the social resources or the opportunity offered to people where he lives [20]. Second, consider the individual characteristics and related resources in the community, for example, age and gender [21], religion [22], marital status [23]. Third, consider the characteristics of biological factors and individual psychology [24].

The study aims to first, look at the characteristics of individuals. Second, understand subjective wellbeing in relation to the experience of the elderly deal with social change on the value of life in the order of religious life more modern (religious values) and individual characteristics.

\section{RESEARCH METHOD}

The study was conducted in Surabaya. The sampling frames were listed that registers elderly people aged 70+ years. The result was that 242 people were selected with probability. The face to face interviews were local residents using a structured questionnaire. Did not ask specifically about religion, but rather seeks to explore more widely in the construction of the meaning of life and identity. Characteristics of individuals based on age, sex, marital status, education, and employment.

\subsection{Philadelphia geriatric center morale scale (PGCMS)}

The instrument using Philadelphia geriatric center morale scale (PGCMS). The PGCMS questionnaire was designed to measure of psychological wellbeing for social gerontological studies [25]. Instrument consists of seventeen items in three subscales of agitation (6 items), attitude towards own ageing (5 items) and lonely dissatisfaction (6 items). Scoring: Each high-morale response receives a score of " 1 " and each low- morale response a score of "0". The total score ranges from 0-17. Guideline, scores at 13 to17 would be considered high scores on the morale scale, 10 to 12 fall within the mid-range and scores under 9 are at the lower end. Internal consistency was measured using Cronbach Alpha $=0.504$. 


\subsection{Self spirituality and religiosity}

The instrument using self-ascribed spirituality and religiosity [26]. The instrument report selfspirituality and religiosity likely influences subjective wellbeing. Three items were used to measure spirituality and two items measured perceived religiosity. Response options for all items were 'strongly agree,' 'agree,' 'neutral,' 'disagree,' and 'strongly disagree'.

\section{RESULTS AND ANALYSIS}

\subsection{Characteristic elderly}

The age ranged from 70 to 90 , a mean age of 76.72. The classification elderly (70-74) was $38 \%$, old (75-90) was $62 \%$. More than one-half elderly $65.3 \%$ was female and $34.7 \%$ was male. The marital status of elderly $47.1 \%$ was marriage, $31.8 \%$ widow/widower and $21.1 \%$ elderly was alone. The religious affiliation of mostly elderly is $90.3 \%$ Moslem, $3.7 \%$ Protestant and 5\% Catholic.

Level of education $78.9 \%$ was elementary school, $4.5 \%$ was junior school and $16.5 \%$ was high school. The majority of elderly $88.8 \%$ was not work, $5.4 \%$ of elderly was pension, and $5.8 \%$ of elderly was work.

\subsection{Self-spirituality and religiosity}

Descriptive statistics for each study can be seen in Table 1. most respondents are reported being low of spirituality and religiosity in their lives.

Table 1. Descriptive Statistics for Self-spirituality and Religiosity

\begin{tabular}{|c|c|c|c|c|c|c|c|}
\hline \multirow{2}{*}{ Variable } & \multirow{2}{*}{ Range } & \multicolumn{2}{|c|}{ Male } & \multicolumn{2}{|c|}{ Female } & \multicolumn{2}{|c|}{ Total } \\
\hline & & Mean & Median & Mean & Median & Mean & Median \\
\hline I am very religious & $1-5$ & $3.05(1.211)$ & 3 & $3.16(1.148)$ & 3 & $3.12(1.169)$ & 3 \\
\hline I am very spirituality & $1-5$ & $3.83(1.118)$ & 4 & $3.68(1.016)$ & 4 & $3.74(1.053)$ & 4 \\
\hline Rely on higher power & $1-5$ & $3.64(1.06)$ & 4 & $3.48(0.922)$ & 3 & $3.54(0.973)$ & 4 \\
\hline
\end{tabular}

Table 2 describes that the results of factor analysis showed that there are two dimensions. It is a religiosity dimension and spirituality dimension. The dimension, religiosity' relates to self-perceived. The dimension 'spirituality' with regard to how people are redefining the meaning of life.

Table 2. Analysis Factor of Religiosity and Spirituality Scale

\begin{tabular}{lcc}
\hline & Factor 1 & Factor 2 \\
\hline Religiosity & & \\
Religion important & -0.028 & 0.802 \\
I am very religious & -0.057 & 0.801 \\
Spirituality & & \\
Spirituality important & 0.770 & -0.062 \\
I am very spirituality & 0.899 & -0.049 \\
Rely on higher power & 0.865 & -0.021 \\
\hline
\end{tabular}

\subsection{Philadelphia geriatric center morale scale (PGCMS)}

The mean PGCMS score was 7.89, with range 1-14. The median PGCMS score was 8, 57.4\% (139) score PGCSM above the median and 42.6\% (103) score PGCSM under the median. This mean showed relatively good physical and mental function. Among elderly who were included the high wellbeing category (PGCSM $\geq 10$ ) was $27.2 \%$ and most of elderly $72.7 \%$ didn't have good wellbeing. In Korean, score PGCMS more than 10.8 and median score was 10 [27]. This showed the subjects were higher wellbeing. This difference related educational level, household income and personal income. The differences between median PGCMS score male was 7.5 with range 2-13. The median PGCMS score female was 8 with range 1-14.

The study show correlation between religiosity and PGCMS $=0.484$, the relationship between was low. The correlation between spirituality and PGCMS $=0.115$, the relationship between was low. It may have relationship by characteristic individual and religion value. In the study, self-religiosity and spirituality and characteristics individual are included as variables to obtain understanding the relationship between selfreligiosity and spirituality and PGCMS. 


\subsection{Exploration of characterics using graph}

Relationship between self-religiosity and spirituality and subjective wellbeing shows that first, age fluctuate with increasing good wellbeing and perceive self-spirituality (Figure 1b), this means elderly perceive good physical and mental function. Second, elderly $\geq 85$ years are more 'spiritual' (Figure 1b). Third, elderly 70-79 years are more 'religious and good wellbeing' than elderly $\geq 80$ years (Figure 1a). Fourth, graph fluctuates at around mean of factor score religiosity (Figure 1a).

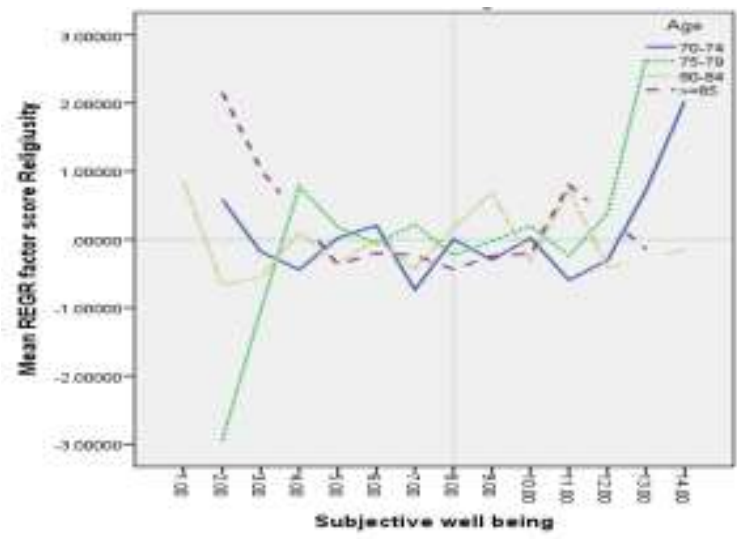

(a)

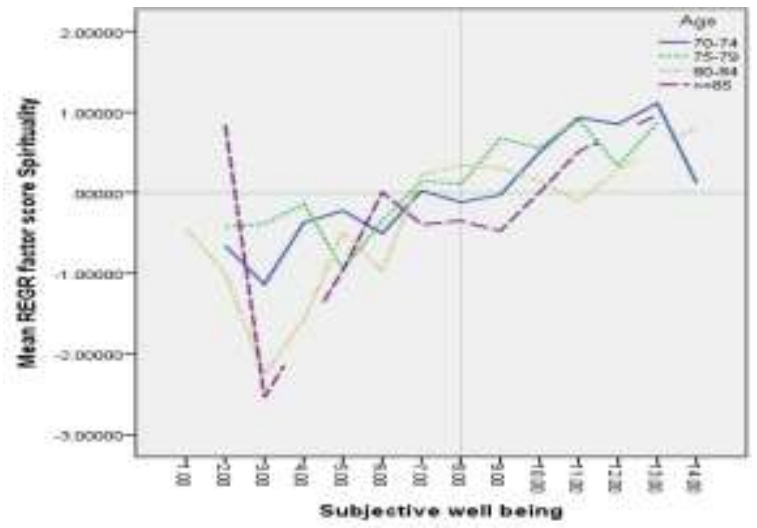

(b)

Figure 1. Religiosity and spirituality and subjective wellbeing according age group

Note: Median subjective wellbeing $=8 ;$ mean factor score $=0$

Relationship between self-religiosity and spirituality and subjective wellbeing shows that sex fluctuate with increasing good wellbeing and perceive self-spirituality (Figure 2b), this means elderly perceive good physical and mental function. Graph fluctuates at around mean of factor score religiosity. The graph relative constants in around mean of factor score (Figure 2a). Fourth, both the graph relative has the shape same model (Figure 2a).

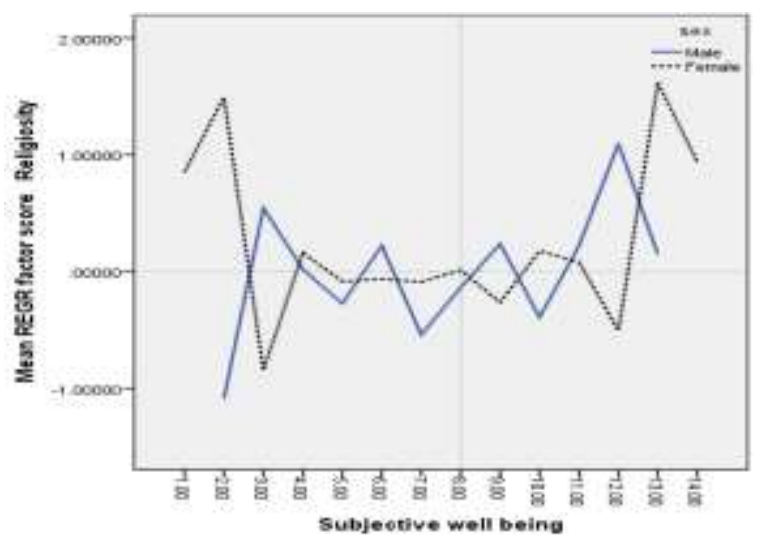

(a)

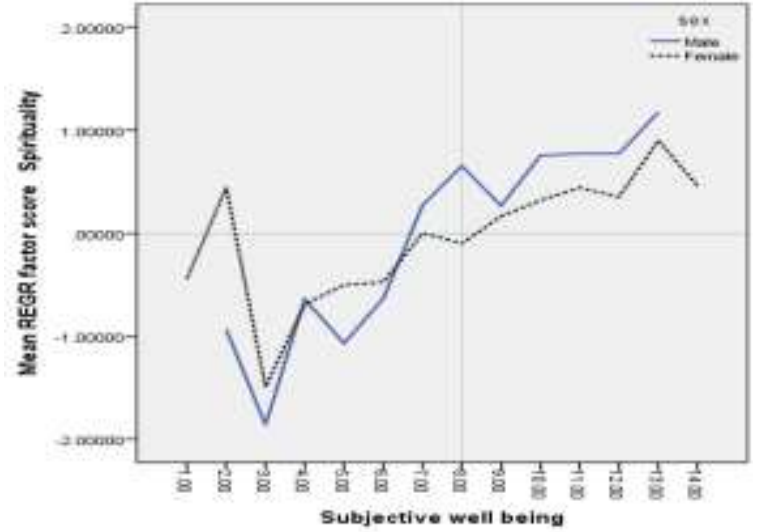

(b)

Figure 2. Religiosity and spirituality and subjective wellbeing according sex

Note: Median subjective wellbeing $=8$; mean factor score $=0$ 
Relationship between self-religiosity and spirituality and subjective wellbeing shows that first, marital status fluctuate with increasing good wellbeing and perceive self-spirituality (Figure 3b). Second, elderly alone are more 'spiritual' and have a good wellbeing (graph increasing). Third, graph fluctuates at around mean of factor score religiosity. The graph relative constants in around mean of factor score (Figure 3a).

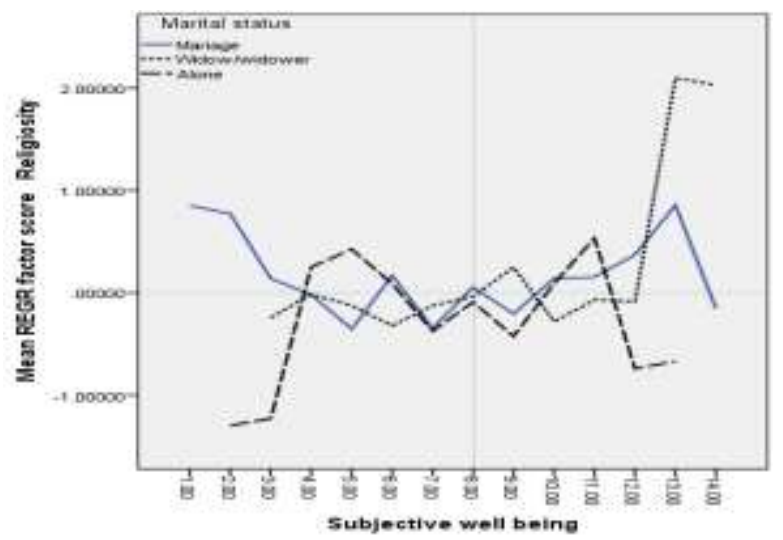

(a)

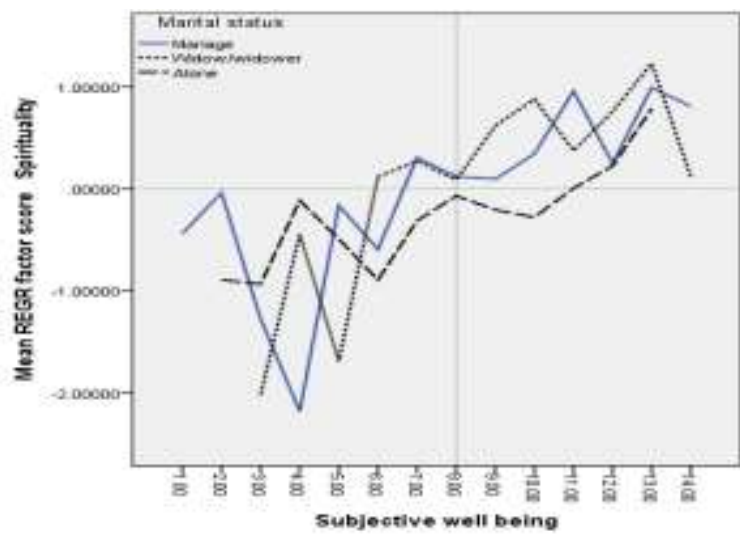

(b)

Figure 3. Religiosity and spirituality and subjective wellbeing according marital status

Note: Median subjective wellbeing $=8$; mean factor score $=0$

Relationship between self-religiosity and spirituality and subjective wellbeing shows that first, level of education fluctuate with increasing good wellbeing and perceive self-religiosity and spirituality (Figure 4a). Second, elderly with junior school are more 'spiritual' and have a good wellbeing (graph move increasing above value zero). Third, graph increasing after mean of factor score spirituality (Figure $4 \mathrm{~b}$ ).

The influence of religious value to elderly (70-74) effects on receipt of the meaning of life. The graph of relationship between self-spirituality and subjective wellbeing shows that age 70-74 more selfspiritual. Among elderly who were included the high wellbeing but decreasing self-spiritual or they were not improve themselves in seeking a meaning of life.

The influence of religiosity to elderly women's subjective wellbeing is rapid. This study identify that the role of spirituality in the live of elderly woman is lower but women have good wellbeing. The median subjective wellbeing score female more higher than male.

The influence of religiosity to elderly alone's subjective wellbeing is slow. Although there is no difference subjective wellbeing and marital status but the influence of spirituality and subjective wellbeing to elderly who live alone is good.

Religion is an element of human life. Religion is not affected by the characteristics of the individual. Religion is the foundation of one's life because it is an essential element of human life so that relatively constant at around zero. Although the religious life one can go up and down but in unsure as human will always miss life values. This is proof of the graph that although fluctuated but stable at around zero. These results research proved that religion is a control in life [28] required by each individual (whether male or female).

Relationship with yourself as the private domain is related to the values of life (spiritual). In an effort to make sense of life, the individual needs to be aware of and respond to a situation, event, and the environment by doing a fabrication of the individual. This situation seems to be influenced by individual characteristics such as sex, journey in the life of the second age, experience marital status, and level of education. Results of the research showed that spirituality in life much of it would be determined by an individual's upbringing, life events and experiences, current circumstances, level of religiousness and spiritual awareness [29-30]. 


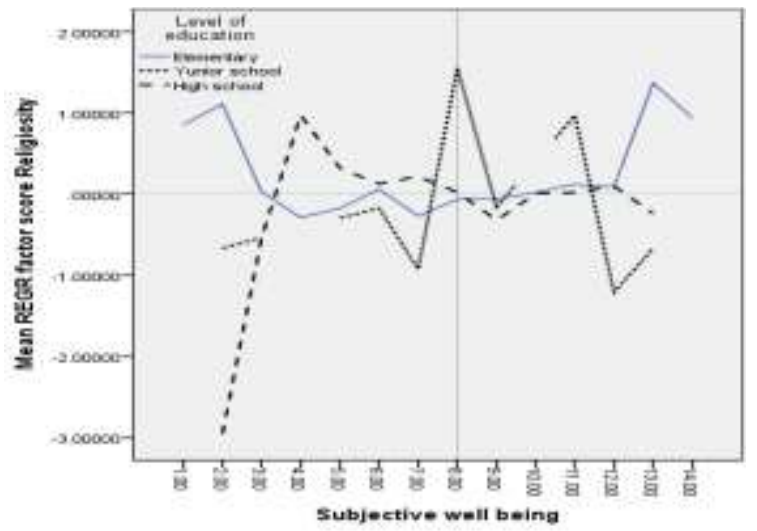

(a)

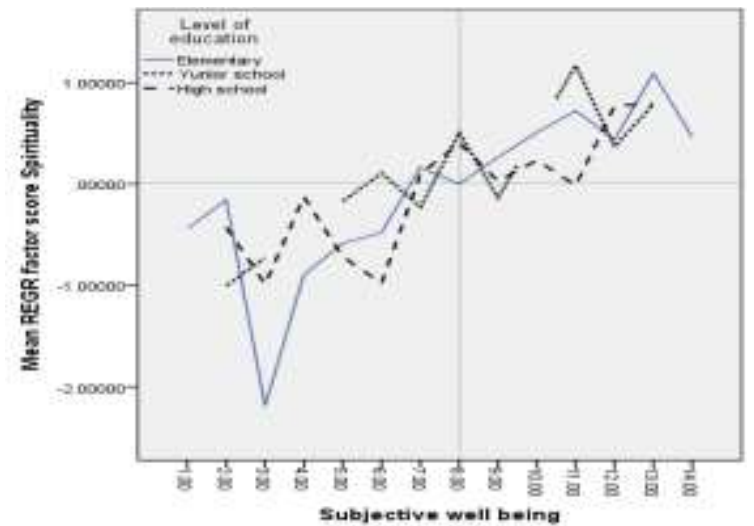

(b)

Figure 4. Religiosity and spirituality and subjective wellbeing according level of education

Note: Median subjective wellbeing $=8 ;$ mean factor score $=0$

\section{CONCLUSION}

According to the results of exploration the graph showed that religiosity value in live of elderly relative constant in around mean factor score. Subjective wellbeing and self-spirituality show a pattern that increasing showed elderly have a view about the meaning of life. Elderly's perception of meaning of life depends on the resources, knowledge, and experience in which individuals live.

Elderly's religious commitment influence on cultural setting and where most of them are Moslem. Exploring how religiosity into subjective wellbeing of elderly living is clear.

Elderly in their marital status are affected by the degree of subjective wellbeing. The exploration indicates that it may be depend on elderly make life satisfaction judgments. Elderly levels of subjective wellbeing are widely varied.

\section{ACKNOWLEDGEMENTS}

The authors are grateful to respondent for its participation and support of research.

\section{REFERENCES}

[1] Central Bureau of Statistic of East Java Province, "Towards a New Era of East Java Province The Analysis of Population Profile Results of Population Census 2010," Surabaya, Central Bureau of Statistic, 2011.

[2] United Nations Population Division, "World Population Ageing: 1950-2050," New York, United Nations Publications, 2002.

[3] Central Bureau of Statistic of East Java Province, "East Java in Figures 2013," Surabaya, Central Bureau of Statistic, 2013a.

[4] Central Bureau of Statistic of East Java Province, "National Socio-Economic Survey of 2012 East Java," Surabaya, Central Bureau of Statistic, 2013b.

[5] Central Bureau of Statistic of East Java Province, "Labor Force Condition in East Java 2012 East Java Province," Surabaya, Central Bureau of Statistic, 2013c.

[6] G. Hugo, "Ageing in Indonesia: A Neglected Area of Policy Concern," in D.R. Phillips (Ed.), "Ageing in East and South-East Asia," London, Edward, pp. 207-230, 1992.

[7] T. Kaneda and Z. Zimmer, "Education, Gender, and Functional Transitions among Indonesia Elderly," Journal Cross Culture Gerontology, vol. 22, pp. 303-322, 2007.

[8] WHO, "Global Health and Aging, National Institute on Aging National Institutes of Health," U.S. Department of Health and Human Services, 2011. Available at http://www.who.int/ageing/publications/global_health.pdf.

[9] Health Office of East Java Province, "Health Profile in East Java province 2011," Surabaya, Health Office of East Java Province, 2012.

[10] Health Office of East Java Province, "Health Profile in East Java province 2012," Surabaya, Health Office of East Java Province, 2013.

[11] S. T. Hunter, "Can Islam and Modernity be Reconciled?" Insight Turkey, vol/issue: 11(3), pp. 1-12, 2009.

[12] C. Young and C. Koopsen, "Spirituality, Health, and Healing," Medan, Bina Media Perintis, 2007.

[13] S. C. White, "Beyond the Paradox: Religion, Family and Modernity in Contemporary Bangladesh," Modern Asian Studies, vol/issue: 46(5), pp. 1429-1458, 2012. 
[14] I. A. Kodzi, et al., "Understanding Ageing in Sub-Saharan Africa: Exploring the Contributions of Religious and Secular Social Involvement to Life Satisfaction," Aging \& Society, vol. 31, pp. 455-474, 2011.

[15] C. E. Westgate, "Spiritual Wellness and Depression," Journal of Counseling and Development, JCD, vol/issue: 75(1), pp. 26-35, 1996.

[16] C. Lim and R. D. Putnam, "Religion, Social Networks, and Life Satisfaction," American Sociological Review, vol/issue: 75(6), pp. 914-933, 2010.

[17] C. M. Neill and A. S. Kahn, "The Role of Personal Spirituality and Religious Social Activity on The Life Satisfaction of Older Widowed Women," Sex Roles, vol/issue: 40(3/4), pp. 319-329, 1999.

[18] M. Williams, "Spirituality of the Elderly," AARN, vol. 47, pp. 25-27, 1991.

[19] M. T. M. Sastre, "Lay Conceptions of Well Being and Rules Used in Well Being Judgments among Young, Middle Aged, and Elderly Adults," Social Indicators Research, vol/issue: 47(2), pp. 203-231, 1999.

[20] E. Diener, "A Value Based Index for Measuring National Quality of Life," Social Indicators Research, vol. 36, pp. 107-127, 1995.

[21] R. Inglehart, "Culture Shift in Advanced Industrial Society," Princeton University Press, Princeton, New Jersey, 1990.

[22] K. I. Maton and E. A. Wells, "Religion as A Community Resource for Well Being: Prevention, Healing, and Empowerment Pathways," Journal of Social Issues, vol. 51, pp. 177-193, 1995.

[23] G. R. Lee, et al., "Marital Status and Personal Happiness: An Analysis of Trend Data," Journal of Marriage and the Family, vol. 53, pp. 839-844, 1991.

[24] P. T. Costa and R. R. McCrae, "Personality as a Lifelong Determinant of Well Being, Emotion in Adult Development," Sage, Beverly Hills, California, pp. 141-156, 1984.

[25] M. P. Lawton, "The Philadelphia Geriatric Center Morale Scale: A Revision," Journal of Gerontology, vol/issue: 30(1), pp. 85-89, 1975.

[26] K. J. Zullig, et al., "The Association between Perceived spirituality, religiosity, and Life Satisfaction: The Mediating Role of Self-Rated Health,” Social Indicators Research, vol. 79, pp. 255-274, 2006.

[27] S. N. Jang, et al., "Association of Socioeconomic Status with Successful Ageing: Differences in the Components of Successful Ageing," J.Biosoc.Sci, vol. 41, pp. 207-219, 2009.

[28] K. I. Pargament, et al., "The Many Methods of Religious Coping: Development and Initial Validation of the RCOPE,” Journal of Clinical Psychology, vol/issue: 56(4), pp. 519-543, 2000.

[29] M. Ahmad and S. Khan, "A Model of Spirituality for Ageing Muslims," J.Relig Health, 2015.

[30] K. K. Mehta, "The impact of religious beliefs and practices on aging: A Cross-cultural comparison," Journal of Aging Studies, vol/issue: 11(2), pp. 101-114, 1997. 